English Language and Linguistics, 23.4: 855-877. C Cambridge University Press 2019. This is an Open Access article, distributed under the terms of the Creative Commons Attribution licence (http://creativecommons.org/licenses/by/4.0/), which permits unrestricted re-use, distribution, and reproduction in any medium, provided the original work is properly cited.

\title{
Proper name compounds: a comparative perspective ${ }^{1}$
}

\author{
ARTEMIS ALEXIADOU \\ Humboldt Universität zu Berlin \\ Leibniz-Zentrum Allgemeine Sprachwissenschaft \\ (Received 5 June 2018; revised 20 January 2019)
}

\begin{abstract}
The article discusses compound formation involving proper names from a comparative perspective. While proper names can appear within compounds in English, this is not possible in Greek. The article argues that this follows from a basic difference between English and Greek: English, but not Greek, allows phrases as non-heads of right-headed compounds. As proper names in English are referential in the absence of a determiner, due to the process of D-N merger, they can still be recognized as such within compounds. This is not possible in Greek, where proper names require the presence of a determiner to establish reference.
\end{abstract}

Keywords: proper names, (phrasal) compounds, noun modifiers, genitive

\section{Introduction}

In Germanic languages, e.g. English (1), German (2) and Swedish (3), proper names can appear in deverbal synthetic compounds (SCs) (Giegerich 2004; Borer 2005; Breban 2018 and references therein for English; Schlücker 2013 for German; Koptjevskaja-Tamm 2013 for Swedish).

(1) Kerry supporter

(2) Goethe-Verehrung

'Goethe adoration'

(3) Palmemord-et

'the Palme murder'

In these languages, proper names can appear in root compounds as well, illustrated here with English:

(4) Rembrandt year

Proper names in such compounds refer to persons well known within the speech community, as detailed in Koptjevskaja-Tamm (2013). According to Koptjevskaja-Tamm (2013), proper name compounds (henceforth PNCs) are intriguing for the following reasons:

\footnotetext{
${ }^{1}$ I am indebted to two anonymous reviewers and the editors of this volume for their comments. Many thanks to Gianina Iordachioaia and audiences at Humboldt University in Berlin and the University of Thessaloniki for discussions. AL 554/8-1 is hereby acknowledged.
} 
(i) since proper names themselves are often phrases rather than single words, the non-head of PNCs can be a phrase

(ii) PNCs are often involved in competition with syntactic coding strategies

(iii) the proper names in PNCs are occasionally accessible for external anaphora.

The focus of this article is a case of cross-linguistic variation: while PNCs are very productive and well-formed in Germanic languages, English being here the main language under discussion, they are ill-formed in Greek. This has been discussed in Ntelitheos (to appear) and Michelioudakis \& Angelopoulos (2013) for SCs (5a-b), but also holds for root compounds (5c). While (5a), from Ntelitheos (to appear), could be argued to be ungrammatical, as it does not refer to a well-known individual in the speech community, this does not hold for $(5 b)$ and $(5 c):^{2}$

(5) (a) *Giorg-o-thavmastis

Giorgo-LE-admirer

(b) *Tsipr-o-thavmastis

Tsipras-LE-admirer

(c) *luthir-o-etos/*luthir-o-hronia

Luther-LE-year/Luther-LE-year

This asymmetry is even more puzzling, as Greek can build both SCs, (6a), and root compounds, (6b), which are similar, yet not identical to their Germanic counterparts (Ralli 2013; Ntelitheos to appear; Alexiadou 2017a; Iordachioaia et al. 2017). One important difference is the presence of the linking element (LE), $-O-:^{3}$

(6) (a) thiri-o-damastis

animal-LE-tamer

(b) kras-o-potiro

wine-LE-glass

The only possibility to form a counterpart of (1)-(3) is to make use of a genitival construction, as in $(7 \mathrm{a}-\mathrm{b})$, or to form an adjective out of the proper name and use it as a noun modifier $(7 \mathrm{c})$ :

(7) (a) thavmastis

*(tu) Tsipra

admirer

the Tsipras-GEN

2 In (5c) I use both the high register etos and the low register hronia corresponding to English 'year' and the compound is impossible with both. With respect to (5a-b), note that Tsipro-latris, i.e. Tsipras-admirer, where the head belongs to the archaic vocabulary of Greek, is acceptable. These cases will not be discussed here, as there is quite some debate concerning the status of the head, i.e. affix-like vs word (Ralli 2013, and references therein). What is important for my discussion here is that no compound can be built containing a head of the type in $(5 \mathrm{a}-\mathrm{b})$, which is clearly a deverbal nominal and a word that can occur on its own.

3 According to Ralli (2013), the linking element has no syntactic status, nor does it contribute any semantic information; it is simply a phonological reflex. As Ralli shows, this element is normally obligatory and it is not inserted when the following two conditions hold: (i) when the head element of the compound begins with a vowel higher in the sonority scale than -o-, and (ii) when the non-head member of the compound is itself an inflected word. This is the case in the so-called word-word compounds that we will see in section 2. 
(b) etos Luthiru

year Luther-GEN

(c) tsipri-es idees

Tsipras-ADJ ideas

While (7a) is a deverbal nominalization, (7b) corresponds to a N-NGEN left-headed phrasal compound known from Romance, as will be discussed in section 2. Thus, we can reformulate the puzzle: while in English phrases can appear as non-head elements in right-headed compounds, this is not possible in Greek. In Greek, this is only possible in left-headed compounds, as is the case in Romance. As (7a) shows, it is impossible to leave out the determiner in the case of the deverbal nominalization, supporting the conclusion that there are no phrasal compounds in Greek with a deverbal head; see Alexiadou (2017a). In (7b) the genitive is non-referential and seems to provide the name for the year, similar to proper noun modifiers in English. Examples such as (8), found online, do not challenge this generalization, as (8) involves a coordination structure. Coordination structures have been shown to license bare singulars even in languages such as English that disallow them. Heycock \& Zamparelli (2003) argue extensively that coordinated bare nouns have an interpretation that is very close to that of definite noun phrases, and the Greek data seem to support their overall conclusions. ${ }^{4}$

4 Their argument is based on contrasts between coordinated and uncoordinated noun phrases in English, as in (i), and similar contrasts are observed in Romance:

(i) A black cat and a brown dog were fighting in the street.

(a) [Cat and dog] were equally filthy.

(b) *Cat was filthy. (Heycock \& Zamparelli 2003: 443)

This leads them to formulate the following generalization (Heycock \& Zamparelli 2003: 450):

(ii) Bare noun coordinations (can) have the semantics of unmodified definites.

While Greek allows bare singulars in object positions (Alexopoulou, Folli \& Tsoulas 2013), and as we will see later on, bare proper names with a non-referential interpretation in argument positions, it crucially does not allow proper names to occur bare in any argument position (subject or object) preserving a referential interpretation:

(iii) (a) *Tsipras episkeftike ton Proedro

Tsipras-NOM visited the President-ACC

(b) *ida Tsipra

saw.1sG Tsipra-ACC

Interestingly, in headlinese, it is possible to use the proper name without an article in the nominal domain, as in (iv). This has been noted in passing in Lazaridou-Chatzigoga (2009: 189) for common nouns in Greek, and I think it is more salient for proper names:

(iv) (a) episkepsi Tsipra sti Mosha

visit Tsipra-GEN to Moscow

'Tsipras's visit to Moscow'

(www.cnn.gr/news/politiki/story/157412/episkepsi-tsipra-sti-mosxa-xekinise-tis-ypsiles-epafes-o-ellinasprothypoyrgos)

(b) triamvos Tsitsipa

triumph Tsitsipa- GEN

'Tsitsipas's triumph'

(www.protothema.gr/sports/article/857026/triumph-tsitsipas-stin-australia-nikise-ton-megalo-federer/) 
$\begin{array}{cll}\text { (8) thavmastis } & \text { Tsipra } & \text { ke Varoufaki } \\ \text { admirer } & \text { Tsipras-GEN } & \text { and Varoufakis-GEN }\end{array}$

The second issue that will concern me here relates to the additional ways a proper name may combine with another noun in the two languages: in English, next to the PNC there are two genitival constructions, the so-called Saxon genitive as well as post-nominal genitive, e.g. Kerry's supporter, supporter of Kerry and Kerry supporter. In Greek only the post-nominal genitive is available, $(7 \mathrm{a}-\mathrm{b})$, whereby, as just mentioned and as we will see in detail, the nominalization behaves differently from the phrasal compound; alternatively, the adjectival formation in (7c) can also be employed. There are of course differences between all these cases, which I will revisit in section 4 .

The aim of this article is thus to offer an explanation for these two observations: (i) no proper name can appear as the non-head member of a right-headed SC or root compound in Greek, as opposed to English; (ii) no proper name can appear as the non-head element of phrasal left-headed deverbal compound, while it can appear in this position when the head is not deverbal. I will use the Greek vs English contrast as a tool to understand the structure of compounds. Specifically, I will address the following questions: (a) why is it impossible to form a compound with a proper name in Greek, while this is possible in English? (b) What does the above puzzle tell us about the structure of compounds and the nature of proper names in Greek and English and generally across languages? As I will show, the behavior of Greek vs English PNCs is a general reflex of the compounding parameter proposed in Ralli (2013) and further supported in Ioardachioaia et al. (2017), according to which languages fall into two groups: those that have non-phrasal left hand non-heads like Greek vs those that have phrasal left hand non-heads like English. Assuming that proper names are phrases, the ban of PNCs in Greek is a reflex of this property: while in English compounding involves phrasal elements as non-heads, in Greek it must involve roots as non-heads. I will also argue that there is a difference with respect to the structure of proper names in the two languages. As proper names are obligatorily DPs in Greek in order to yield rigid designation, this leads to a general ban on compound formation involving proper names in the language. The only possible way to express a meaning close to that of compound is thus via the genitival or the adjectival construction, as in $(7 b-c)$. Proper names in English are phrasal and can refer to individuals, because D and $\mathrm{N}$ combine. As English compounding involves phrases in general, there is no blocking of PNCs. As such a merger is not an option in Greek, PNCs are out. Turning to the second observation, i.e. the type of head in left-headed compounds, deverbal vs root, the ban on PNCs with deverbal heads relates to the fact that Greek simply does not form phrasal compounds of this sort, as will be discussed in section 2 .

The article is structured as follows: in section 2, I present a detailed description of Modern Greek compounding. In section 3, I turn to the status of proper names in

As is well known, articles can be dropped from common nouns in English headlinese as well, but not much is known about the features of this particular register in Greek. The fact that proper names can appear without an article in the nominal domain but not with verbal predicates suggests that headlinese generalizes the N-N $\mathrm{NEN}_{\mathrm{N}}$ pattern, when specific reference can be recovered from the context. 
Greek as opposed to English and offer an account that explains their properties. I also discuss in detail the restrictions on compounding. In section 4, I turn to an analysis of the two compound structures and then to a comparison between Greek and English genitival constructions. In section 5, I conclude and discuss some interesting consequences of the analysis puts forth in this article. I will point out that the explanation offered here might help us understand another cross-linguistic puzzle on compounding, namely the lack of quotation compounds in Greek as opposed to English.

\section{Compounding in Greek}

Ralli (2013) distinguishes between three types of compounds, stem-stem (9a), stemword compounds (9b) and word-word, i.e. phrasal compounds (9c-d) (see also Kechagias 2005).

(9) (a) níhta lulúdi night flower

(b) thrirío damastís beast tamer

(c) antropos arahni man spider

(d) praktorio idiseo agency news-GEN

$\begin{array}{ll}\begin{array}{l}\text { niht-o-lúludo } \\ \text { night-LE-flower }\end{array} & \text { stem-stem } \\ \text { thiri-o-damastís } & \text { stem-word } \\ \begin{array}{l}\text { beast-LE-tamer } \\ \text { spider-man }\end{array} & \mathrm{N}-\mathrm{N} \\ \text { news agency } & \mathrm{N}-\mathrm{N} \text { GEN }\end{array}$

niht-o-lúludo stem-stem

thiri-o-damastís stem-word

The first two types are right-headed structures while the third one is a left-headed structure of the type familiar from Romance languages. The first type involves inflectional and phonological variation, as the compound element bears a different stress from the pattern the two members would bear in isolation. According to Ralli, both the head and the non-head are stems. In the second type, the non-head is obligatorily a stem, while the head of the compound bears the same set of inflectional affixes that it would have in isolation, and thus qualifies as a word. These two types are the ones that contain a linking element. Ralli (2013: 59) convincingly distinguishes the linking element from the inflectional endings of the non-head and I will adopt her conclusions here; see footnote 2 . These two types also have in common that they form a single stress domain.

The third type comes in at least two variants, N-N and N-NGEN, i.e. either the two nouns agree in case, as in (9c), or the non-head which is on the right surfaces with genitive case, as in (9d). In both instantiations, we have two stress domains. As Ralli (2013:248) details, the constituents that build the third type lack syntactic autonomy, as the non-head cannot be modified, their order cannot be reversed, and nothing can intervene between the two constituents. Importantly, however, they involve phrasal elements as non-heads, as can be seen by the fact that they bear inflection class markers.

Greek right-headed compounds are subject to the bare stem constraint, according to Ralli (2013), i.e. the non-head must appear as a bare stem. Ralli uses the label stem in her work to emphasize the fact that in principle this form could not stand in isolation and cannot carry any type of inflectional or derivational morphology. This means that 
non-heads are morphosyntactically dependent: as Ralli (2013: 133-4) notes, non-heads disallow both derivational and inflectional suffixes. A derived noun like player is not possible in a compound, as in (10a). Such nouns are categorized as words and have to be part of analytic compounds, as in (10b) ( $\mathrm{NZ}=$ nominalizer).
(a) *peh-t-o-timoría
vs
play-NZ-LE-punishment
(b) timoría
pek-t-ón
punishment play-NZ-GEN

Ralli argues that this relates to the characteristic property of Greek as a stem-based language. I will use the term root here to refer to what Ralli calls stem, as I take it that these forms have not been categorized as bearing nominal features What this crucially amounts to is that the language does not allow roots to surface as words without carrying any inflection, where it essentially differs from English. In other words, a noun in Greek always bears inflection and gender features; see Alexiadou (2017b) for a recent discussion. Importantly, it involves the combination of a root together with a particular functional layer where this inflection is introduced. The obligatory presence of the linking element /o/ and the absence of any inflectional marking for declension class (see Ralli 2013) enforces the idea that non-heads in Greek compounding are roots, which are morphosyntactically incorporated. This will be an important ingredient in approaching the ban on PNCs in Greek. When nouns appear with inflectional endings, they must appear in a phrasal compound, as in $(9 \mathrm{c}-\mathrm{d})$. In this case, Ralli's constraint does not hold and the linking element does not appear, as mentioned in footnote 3 .

While formations corresponding to English root compounds can belong to any of these three types in Greek, SCs qualify as stem-word compounds in Ralli's system, as the stress falls on the same syllable of the nominal head as it would if it appeared in isolation; see (9b) and (11): ${ }^{5}$
(11) kapn-o-kaliérgia
kapn-o-kaliergitís
(cf. kapnós; kaliérgia; kaliergitís) tobacco-LE-cultivation tobacco-LE-cultivator tobacco; cultivation; cultivator

${ }^{5}$ Kechagias (2005) shows that this does not hold for all SCs. There are also SCs for which no corresponding verb exists. As in some cases, the N-V verbal form is obsolete, it could be argued that these forms are relics of older N-V verbal compounds (see Alexiadou 2017a for discussion). It is also not clear where in these cases the head functions more like an affix; see footnote 2 .
(i) thavmat-o-pi-Ø-(os) 'miracle maker' anth-o-pól-Ø-is 'flower seller'
(ii) *thavmat-o-pi(o) 'to miracle-make' *anth-o-pol(o) 'to flower-sell'

According to Ralli (2013), there is also a further case of SCs, where the N-V verbal element seems to be a back formation, as illustrated in (iii), where the verbal form in the SC is different from that of the verb in isolation.

$$
\begin{aligned}
& \text { (iii) vivli-o-détis vivli-o-detó déno } \\
& \text { book-LE-binder book-LE- bind bind }
\end{aligned}
$$

Proper names cannot appear in any of the above formations, which would in any case also involve a root as the non-head of the compound. 
Such compounds are not very productive, i.e. some non-heads are better than others:

(12) thiri-o-damastís *alog-o-damastís

beast-LE-tamer horse-LE-tamer

'beast tamer' 'horse tamer'

Unlike root compounds, the non-head functions as the internal argument of both the SC and the N-V verbal compound. Evidence for this comes from the fact that neither SCs, nor their $\mathrm{N}-\mathrm{V}$ corresponding verbal compounds allow the realization of a phrasal argument next to the element that appears as the non-head of both the SC and the verbal compound, as discussed in Iordachioaia et al. (2017).
(13) I Maria thiriodamazi
(*to alogo).
the Mary beast.tames
the horse
'Mary beast tames.'

Ntelitheos (to appear) argues that Greek also has phrasal compounds with a deverbal head, as in (9d); see (14):

(14) damastis thirion

tamer beasts-GEN

'animal tamer/tamer of animals'

Alexiadou (2017a), however, presents a series of arguments that such cases are better analyzed as involving dispositional argument structure nominals. The dispositional interpretation comes from the fact that the argument of the deverbal noun lacks a determiner. These build on Ralli's (2013) criteria for phrasal compounds:

(a) Reversibility: the order of constituents may not be reversed in true phrasal compounds (15a) vs (15b):
(a) zoni asfalias
belt safety-GEN
'safety belt'
*asfalias zoni
safety-GEN belt
(b) epeksergasia dedemenon dedomenon epeksergasia processing data-GEN data-GEN processing 'data processing'

(15b) behaves on a par with other nominal constructions in Greek, where the genitive shows some degree of autonomy, e.g. possessors, as in (16a), and internal argument of nominalizations, as in (16b); see Horrocks \& Stavrou (1987), and Alexiadou (2001). Both the examples in (16) have been argued by Horrocks \& Stavrou (1987) to involve fronting of the genitive to a position higher than the determiner, identified as Spec,DP:
(16) (a) to vivlio tu Jani
tu Jani to vivlio
the book the John-GEN
the John-GEN the book
'John's book'
'John's book' 

(b) i katastrofi
tis polis
tis polis
i katastrofi
the destruction
the city-GEN
the city-GEN
the destruction
'the destruction of the city'

(b) Insertion of parentheticals: this is not possible in true phrasal compounds (17), but it is possible in examples such as (18):

$*_{i}$ zoni, opos vlepete, asfalias

the belt, as you see, safety-GEN

(18) i epeksergasia, opos vlepete, dedemenon

the processing, as you see, data-GEN

As this is possible with other nominalizations too, (19), Alexiadou (2017a) concludes that there are no phrasal compounds in Greek with a deverbal head:

(19) i katastrofi, opos akusate, tis polis

the destruction, as you see, the city.GEN

I will turn to an analysis of the truly phrasal compound, the N-NGEN pattern in $(9 \mathrm{~d})$ in section 4 .

3 Proper names and compounding in Greek versus English

\subsection{Obligatory determiners in Greek proper names versus English}

An important difference between Greek and English is that in Greek proper names are obligatorily introduced by articles in argument positions:

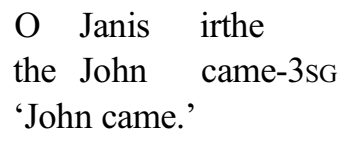

According to one influential approach in the literature (Longobardi 1994), proper names across languages are referring expressions, and as a result a D layer is always present in their morphosyntactic representation. This explains the fact that in English proper names are not introduced by articles in argument positions. According to Longobardi (1994), in English proper names involve N-to-D movement that takes place at LF, i.e. covertly. To the extent that there are languages such as Greek in which proper names co-occur with articles, these articles must be void of semantic import.

However, there is evidence for the fact that in Greek, articles are not expletive, thus providing support for an analysis according to which proper names have the syntax of common nouns, e.g. Borer (2005), Fara (2015), Matushansky (2008). Alexopoulou \& Folli (2011) discuss a number of contrasts involving the behavior of proper names with and without articles in predicative structures and beyond:

(21) tus simvulepse Iudas

them advised-3sg Judas-NOM

'Judas advised them.' 
The proper name Judas appears without the determiner. In this case, the sentence means that someone with the properties of Judas (e.g. a traitor) advised them. Thus, they conclude that the Greek definite determiner is not expletive and, when present, it has a semantic effect, namely, to introduce unique reference. Assuming then a structure of the noun phrase that separates the functional layer of definiteness from that of the lexical content, we can assume (22) for the representation of proper names in Greek: ${ }^{6}$

$$
\begin{gathered}
\text { DP (reference, definiteness) } \\
\quad \text { NP/nP (lexical content) }
\end{gathered}
$$

In English, where proper names occur in compounds, the proper name is recognized as such. ${ }^{7}$ Ghomeshi \& Massam (2009), discussing examples such as Nixon hater, point out that since this is so, the features that are responsible for this must be located at the level of the NP/nP. To explain this, they distinguish between different flavors of $n$, namely common $n$ vs proper $n$.

However, there is an alternative way to capture this without having to assume flavors of n. Matushansky (2006) argues that the proper name and the definite article undergo morphological (m-)merger in English, when nothing intervenes. Specifically, Matushanksy (2006: 296) states that 'm-merger is a strictly cyclic morphological operation that takes two syntactic heads in a certain configuration and returns one syntactic head. It is subject to strict locality: nothing may intervene between the two heads: neither a Spec nor a modifier.' This in turn means that in (22), m-merger takes place in English, but not in Greek, assuming as in Longobardi (1994) that proper names always contain D.

Evidence for m-merger in English comes from the following facts: the determiner is obligatory when the proper name is modified by an adjective or the proper name is plural. Burge (1973: 429) offers the following examples, where a proper name can carry plural morphology and appear after quantifiers, just like common nouns. As is well known, proper names obligatorily co-occur with a determiner if they are plural:

(23) (a) There are relatively few Alfreds in Princeton.

(b) Some Alfreds are crazy; some are sane.

(c) The Clintons

Modification and plurality block m-merger because they intervene between $\mathrm{D}$ and $\mathrm{N}$ : it has been argued by Ritter (1991) that Number is a functional projection between D and $\mathrm{N}$ (24); more recent approaches to the functional architecture of the noun phrase make similar claims, although they use a different label for the projection that hosts plurality, e.g. Borer (2005) and Heycock \& Zamparelli (2005).

\footnotetext{
${ }^{6}$ For the purposes of the argument it does not matter if lexical content is associated with the NP layer, or, as is standard in Distributed Morphology, with the nP layer. I will come back to that in section 4.

${ }^{7}$ In fact, this is the case even with proper names that necessarily require the definite article even in English, e.g. Bronx lover vs The Bronx (Huddleston \& Pullum 2002: 517; Borer 2005).
} 


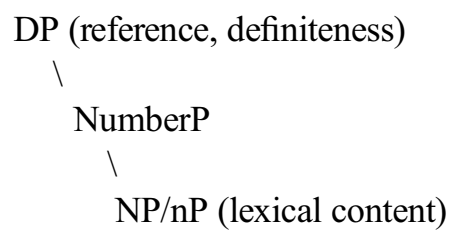

Abney (1987) has argued that adjectives in English are heads in the extended projection of the noun, thus this would also block m-merger of D-N in English. Fara (2015) shows that there are two type of modifiers, those that she labels permissive, which allow the definite determiner with the proper name, as shown in (25), and those that she labels strict, as shown in (26), which obligatorily require the definite determiner. Interestingly, strict modifiers have been argued in the literature to have a head status, i.e. to occupy a head position between $\mathrm{D}$ and $\mathrm{N}$, in the extended projection of the noun. This gives a configuration which would lead to D-N merger blocking:

(25) (a) (The) young Martin would be happy to stay young forever.

(b) (The) brave Philip slew the dragon with just one blow.

(26) (a) The former Mrs Smith was ecstatic about her divorce.

(b) *Former Mrs Smith was ecstatic about her divorce.

We can thus conclude that in English, but not in Greek, D undergoes merger with $\mathrm{N}$ when nothing intervenes, the result being that proper names are recognized as such and are referential even in the absence of an overt determiner. In other words, the contrast between English and Greek is that rigid and unique reference is established via overt D in Greek, while D and N merger is possible in English. Matushansky (2006) does not offer an explanation as to why merger does not take place in some languages, but it is conceivable to think that Greek disallows morphological merger of D and $\mathrm{N}$ as in this language merger always applies between Number and NP/nP, as the language has syncretic nominal morphology; see Alexiadou \& Stavrou (1997). Since Number fuses with $\mathrm{N} / \mathrm{n}, \mathrm{D}$, when present, is realized by an overt determiner. In other words, Number-N/n merger blocks D-N merger; in turn, D receives a realization agreeing with the head noun. This necessarily means that in Greek no noun can appear without inflection class marking; when this happens, then there is simply no NP/nP in Greek, we have units that are smaller than NPs/nPs, i.e. basically roots.

Although I consider the evidence in favor of m-merger substantial, I'd like to point out that for the purposes of this article what is important is that $\mathrm{D}$ and $\mathrm{N}$ always combine under one head in English, while they never do in Greek. M-merger might be one way in which this is done, but it might not be the only alternative.

\subsection{Restrictions on compounding in Greek versus English}

Let us recall the basic restrictions once more. As mentioned in the introduction, although Greek allows (6), it disallows (5), repeated below. 
(5) (a) * Giorg-o-thavmastis Giorgo-LE-admirer

(b) *Tsipr-o-thavmastis Tsipras-LE-admirer

(c) *luthir-o-etos/*luthir-o-hronia Luther-LE-year/Luther-LE-year

(6) (a) thiri-o-damastis animal-LE-tamer

(b) kras-o-potiro wine-LE-glass

The only possibility is to make use of a genitive construction, as in (7a-b), or to form an adjective out of the proper name and use it as a modifier, as in (7c), repeated below:

(7) (a) thavmastis tu Tsipra admirer the Tsipras-GEN

(b) etos Luthiru year Luther-GEN

(c) tsipri-es idees

Tsipras-ADJ ideas

As (7b) shows proper names can appear in left-headed compounds, which are phrasal. However, they cannot appear in a particular type of left-headed exocentric compounds described in Ralli (2013: 113-15). Ralli points out that Greek has some relics of $\mathrm{V}+\mathrm{N}$ compounds, as in (27), which violate the requirement that compounds in Greek are right-headed. The left member corresponds to the Ancient Greek verb 'filo' 'to love':

(27) (a) filo-zo-os

love-animal-MASC.SING

'the one who loves animals'

(b) filo-amerikan-os

love-American-MASC.SING

'the one who loves American people'

Proper names cannot appear in such compounds either, unless they become adjectives: (28) (a) $*$ filotsipras
love-tsipras (b) filo-papandre-ik-os love-papandreu-adj-MASC.SING 'the one who loves Papandreou'

Where a proper name is, however, possible in Greek without a determiner is in N-NGEN phrasal compounds of the type zoni asfalias 'belt safety.GEN'; these do not have a deverbal head:

\footnotetext{
${ }^{8}$ Thanks to Elena Anagnostopoulou for pointing this out to me.
} 
(29) (a) ergo Tritsi

work Tritsi-GEN

'Tritsi work'

(b) nomos Katseli

law Katseli-GEN

'Katseli law'

However, the genitive in these strings does not have an argument status and is not referential. This can be shown by applying Kolliakou's (2003) pronominalization diagnostic. As Kolliakou argues, a pronominal clitic can replace a noun phrase that has independent reference, while it cannot replace a modifier genitive:

(30) (a) o dolofonos tu/tu Jani

the murder his/the John-GEN

(b) to vivlio tis istorias/*to vivlio tis

the book the history-GEN/the book hers

Applying this test to the data in (29), we note that a genitive clitic is possible, but it cannot refer to the proper name if this is not introduced by a determiner:

(31) to ergo tu/tu Tritsi

the work his/the Tritsi-GEN

'his/Tritsi's work'

N-NGEN phrasal compounds contain thus non-referential genitives; see Alexiadou, Haegeman \& Stavrou (2007) for discussion. In the literature, such genitives are referred to as classifying or property genitives. As we will see in section 4 , they behave in a very similar way to proper noun modifiers in English.

A proper name lacking a determiner is very degraded with derived nouns unless these are coordinated, as we saw above in (8). (32) might be found in headlinese, as pointed out in footnote 4 , where the referent both of the deverbal noun and the proper name can be retrieved from the context:

(32) ??thavmastis Tsipra

admirer Tsipra-GEN

Recall that in section 2, I mentioned that Greek does not have phrasal compounds with derived nominal heads and that strings such as (14), repeated below, are best analyzed as dispositional nominalizations:

(14) damastis thirion

tamer beasts-GEN

'animal tamer/tamer of animals'

The analysis of those as dispositional nominalizations adopted the view in Alexopoulou, Folli \& Tsoulas (2013) that bare nouns in Greek do not differ in their distribution from DP arguments. From their point of view, bare nouns are NumberPs in Greek. What Alexiadou 
(2017a) argued is that when such nouns appear with deverbal nominals they lead to a dispositional reading of the overall nominal, which is the case in (14). But, importantly, proper names in argument positions in the absence of a determiner have a simple predicate meaning, i.e. they lack a referential interpretation; see also footnote 4 and (21) above. Thus, to the extent that (32) is possible at all it would force the proper name to be interpreted as a modifier of the head noun similar to the cases in (29). Basically, it would imply that a particular individual would have the profession of being an admirer of someone with the properties of Tsipras, and this is why such structures feel very degraded.

With these remarks then, I will turn to an analysis in the next section. I will argue that the difference seems to be related to size of units that enter compounding, uncategorized stems vs categorized words (Iordachioaia et al. 2017). We saw that Greek forms SCs using stems as non-heads. English, on the other hand, can build SCs on the basis of phrasal elements, i.e. NP/nPs.

\section{Towards an analysis}

\subsection{Differences in compound structures between Greek and English}

In section 3.1, I adopted an analysis, according to which proper names in English D-N combine. My structural analysis is cast within the framework of Distributed Morphology, a basic assumption in which words are complex as they are built in the syntax via combining an acategorial root with categorizers (n, v); see Arad (2005), Embick (2010), Marantz (2013) and others. Crucially then, NPs are viewed as being complex, containing an $\mathrm{n}$ layer that combines with an acategorial root. This is an important assumption that enables us to draw a distinction between compound structures that truly involve roots as opposed to compound structures that involve non-heads which have a phrasal status. As in Greek all inflectional information is on $\mathrm{n}$, the fact that compounds have non-heads which lack such information suggests that these are smaller than nPs. They are basically roots. nPs appear in phrasal compounds, which are right-headed, and in which case they lack determiners, while they carry all other inflectional information.

Iordachioaia et al. (2017) offer a structural analysis of SCs of the type in (33) (cf. Ralli 2002; Anastasiadi-Symeonidi 2002; Kechagias 2005) in the spirit of Ntelitheos, i.e. these involve nominalizations of a verbal compound.

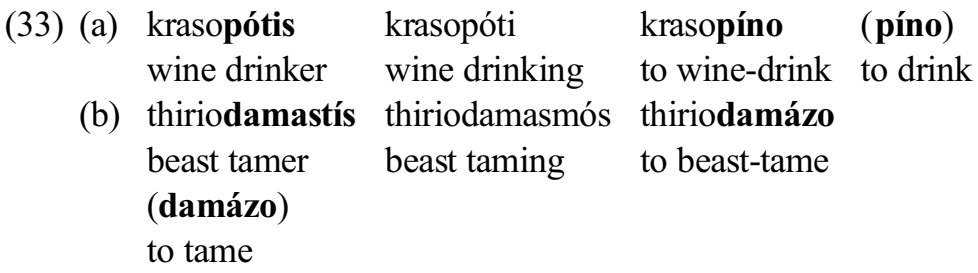

These are examples in which the SC appears to be a nominalization of the N-V verbal compound. According to these authors, (33) involves incorporated roots. Specifically, 
SCs in Greek involve morphosyntactic incorporation, where the non-heads of the SC are roots, which are morphosyntactically dependent, as we have seen above, i.e. stems. The derivation of thiriodamastís ('animal tamer') is as in (34):

(34) thiriodamastís ('beast tamer'); thiriodamazo ('to beast tame')
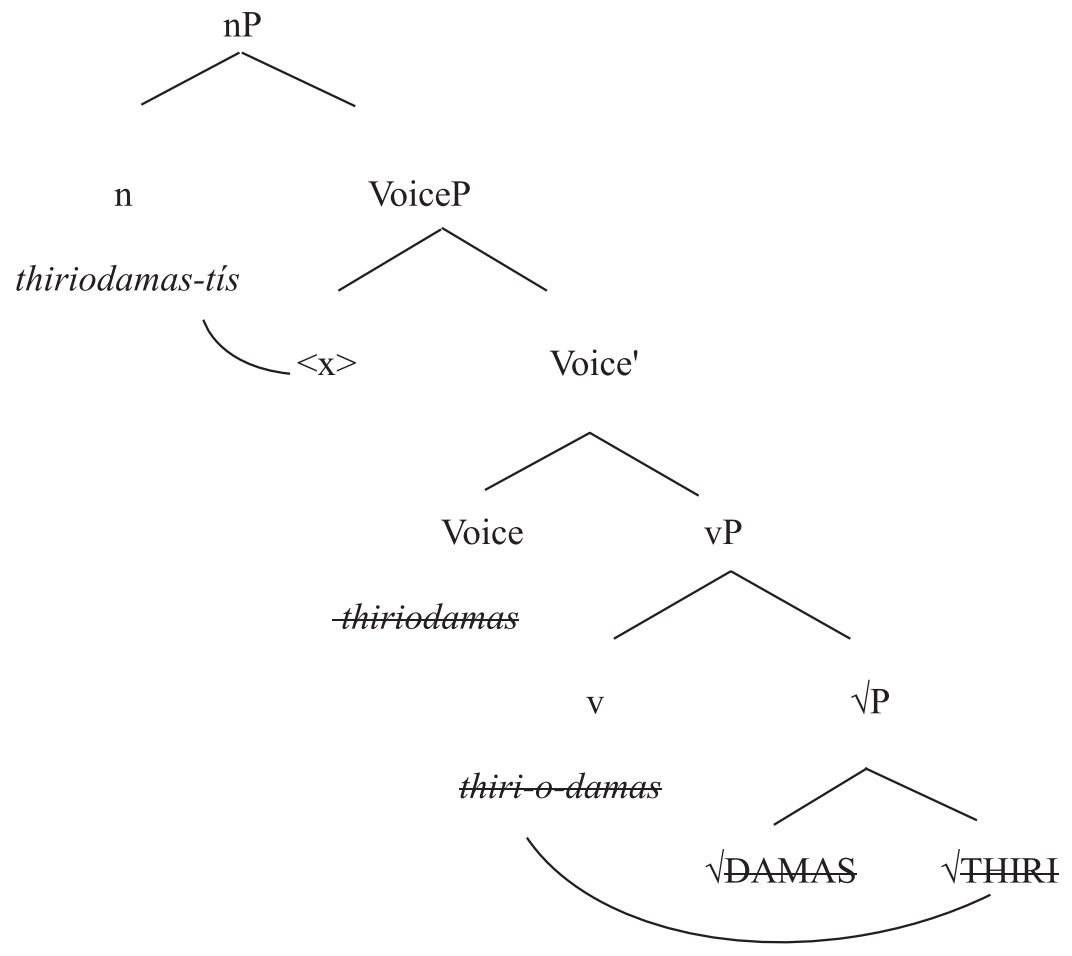

In (34), according to Iordachioaia et al. (2017), the verbal root is categorized as a verb, forming the stem damas for the lexical verb damázo 'to tame'and then root thiri 'beast' moves to $\mathrm{v}$ and incorporates into it, forming the $\mathrm{N}-\mathrm{V}$ compound thiriodamázo, a vP. ${ }^{9}$

This structure basically involves a root incorporation analysis as in Harley (2009) for English (cf. Michelioudakis \& Angelopoulos 2013). Following Ralli (2013), the linking morpheme - $o$ - has no syntactic status, it is simply a phonological reflex, as mentioned in the introduction. This analysis explains, according to Iordachioaia et al. (2017), the limited productivity of Greek SCs as a result of the idiosyncrasy of the non-head roots: some can undergo incorporation, but others cannot, depending on our world

9 The difference between (34) and the cases mentioned in footnote 5, e.g. vivli-o-detó 'book-bind', has to do with the fact that in vivli-o-detó, the two roots combine with the categorizer as a unit. Crucially, in both the SC is a nominalization of a verbal compound. 
knowledge. The opposite holds for English synthetic compounds, which are not constrained along these lines.

These steps enable us now to approach the PNC issue. In Greek, Borer (2005) argues, the formation of a set with a single member necessarily involves the determiner, e.g. o Tsipras. If in Greek, however, right-headed compounds cannot have phrasal non-heads, it is not possible to form a compound that contains a proper name since proper name reference necessarily requires an $\mathrm{nP}$ structure combining with $\mathrm{D}$, which is banned from Greek compounding. Now, in languages with noun incorporation, proper names never incorporate (Baker 1988). This has been argued by some researchers to be related to the fact that proper names cannot be interpreted as general enough to make good candidates for incorporation. While proper names can enter other derivational processes, they lack the unique reference property, as expected, and which we also observe in true phrasal compounds.

In English, according to Borer (2005), proper names involve, in some cases, phonological representations that make reference to a set with a single member (Borer 2005: 85). Following the analysis in section 3.1, this corresponds to a nP and, importantly, it does not require the presence of an article, since we have a combination of D and n. This in turn suggests that SCs in English do not involve root incorporation, as Iordachioaia et al. have argued. In English, the non-head is at least an $\mathrm{nP}$, and the $\mathrm{SC}$ is derived as in (35):

(35) $\left[{ }_{\mathrm{nP}}[\mathrm{nP}\right.$ disposition $]$ lift-er $\left[\mathrm{VoiceP}_{\mathrm{X}}>\right.$ lift $\left[\mathrm{vP}_{\mathrm{P}}\right.$ lift $\left[\sqrt{ }\right.$ LIFT $\left[\mathrm{nP}_{\mathrm{P}}\right.$ disposition $\left.]\right]$

The difference between English and Greek is that the non-head disposition is a noun and not a root. English differs from Greek in that it lacks root incorporation. Rather, what happens is that the verb gets nominalized by the suffix -er and the noun disposition moves to the Spec $\mathrm{nP}$ of the nominalized structure. This is because it cannot be marked for Case and is illicit in this argumental position (cf. Longobardi 1994); thus, it has to move.

Iordachioaia et al. (2017) argue against incorporation in SCs in English. Among other things, as they point out, see also Wiese (1996), non-heads can be morphologically complex. Such strings are impossible in Greek:

(36) season ticket holder, air traffic controller, flight data recorder, child care provider, science fiction writer, ice cream maker, documentary film maker, sports car maker

A similar type of analysis can be given to root compounds of the form Luther year, where the proper name functions as a modifier of the head noun, again situated in Spec,nP. I will come back to this in the next section.

As Rosenbach (2007) observes, such strings deviate from the typical compound stress of English and show phrasal stress; see Plag (2006). This already suggests that compounds involving proper names cannot simply involve the combination of two nouns into a single unit. This is reflected in the analysis in (35). 


\subsection{Greek and English genitive constructions versus compounds}

As I have already mentioned, the counterparts of English compounds are genitival constructions in post-nominal position in Greek. The examples in (37) are argument-supporting nominalizations, i.e. the genitive is the internal argument of the verb that undergoes nominalization:
(a) o dolofonos the murderer
tu Palme
'Palme's murderer'
the Palme-GEN
(b) i ipostiriktes
the supporters
tu Kerry
'Kerry's supporters'

Greek lacks prenominal genitives of the 'Saxon genitive' type; see Horrocks \& Stavrou (1987), Alexiadou (2001). When genitives are fronted, they precede the determiner and thus are analyzed as being located in Spec,DP. The genitives in (38) are clearly referential, as can be shown by applying Kolliakou's (2003) pronominalization diagnostic.

(38) (a) o dolofonos tu

the murder his

(b) to vivlio tis istorias/*to vivlio tis

the book the history-GEN/the book hers

While in Greek the genitive construction is the only option to express the counterparts of English compounds, in English PNCs compete with two other structures: what appears as the non-head of the compound can also appear as a pre- or a post-nominal genitive, as in Greek.

(39) (a) Kerry's supporters

(b) a supporter of Kerry

It is generally agreed upon that the prenominal genitive appears in the Spec,DP position, as in see (40), while the post-nominal one is inside the deverbal noun, as in (41); see Alexiadou (2001). This structure explains why in English the genitive 's never co-occurs with determiners, following Abney (1987):

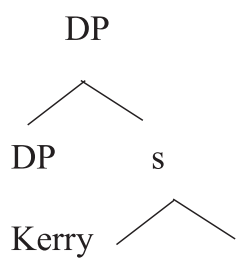


(41)

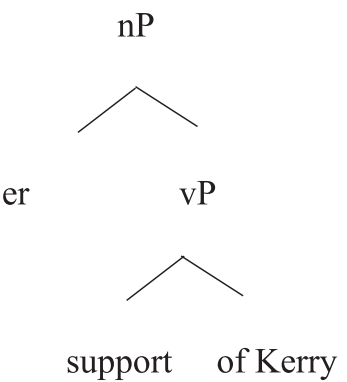

Rosenbach (2007) labels examples of the type Kerry's supporter determiner genitives, while the string Kerry supporter is referred to as a noun-modifier. Notice that this is similar to the Greek cases in (27), the difference being that the modifier appears post-nominally in Greek. Rosenbach shows that there are some differences between noun modifiers and the corresponding prenominal genitive. Whereas the compound Major plan can refer to plan made by John Major or a typical plan by John Major, Major's plan has only the former reading. Recently, Breban et al. (2019) have argued that the situation is not as clear-cut. Rather both constructions can receive a wide range of interpretations. Nevertheless, a typical association of structures is observed in that speakers prefer the genitive construction to express the possessor relation, and the noun modifier one to express the name relation.

In Greek the situation is categorical and regulated by the presence of the determiner in the N-NGEN, see (42): (a) has only the reading of a law made by the minister Katseli, while (b) names the law. This is expected if the determiner is omitted and a determiner always assigns rigid reference in Greek.

(42) (a) o nomos tis Katseli

the law the Katseli-GEN

'Katseli's law'

(b) o nomos Katseli

the law Katseli-GEN

'Katseli law'

In English, proper names in compounds occur immediately before the noun and following other modifiers; the genitive precedes modifiers, again providing evidence that in this case it is located high in the structure. By contrast (43) suggests that the modifier is low, in Spec,nP, as illustrated in (35). As in Greek the genitive appears in post-nominal position in both cases, the contrast cannot be shown the same way. However, the examples in (44) have different readings: (44a) refers to a new law created by Katseli, while (44b) is a new Katseli law, whose creator could be someone else:

(43) (a) the new Major plan/*the Major new plan

(b) Major's new plan 
(44) (a) o neos nomos tis Katseli

the new law the Katseli-GEN

'Katseli's new law'

(b) o neos nomos Katseli

the new law Katseli-GEN

'new Katseli law'

Importantly, Rosenbach notes that noun modifiers can be conjoined with other proper names, but also adjectives, suggesting that they have a similar function. In fact, they seem related to so-called provenance adjectives that appear rather low in the hierarchy of adjectives (Cinque 1993):

(45) (a) The Bush and Clinton administration

(b) The Bush and American administration

Thus, in English the compound structure offers a modifier function, while other roles are in principle possible. In Greek, the modifier function is taken over by the bare genitive: in this case, the genitive noun appearing in the complement domain of the nominal head, as in (46). In this structure, the classifying $\mathrm{nP}$ receives genitive as default (see Alexiadou 2017a), this being the unmarked case for nouns within the noun phrase:

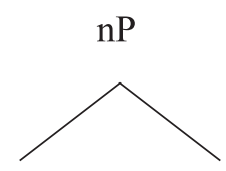

$\mathrm{n}$

nPGEN

Recall further that Greek can have adjectives built out of proper names, which can then modify the head noun; see (47).

(47) papandre-ik-i diahirisi

'Papandreou's management'

These adjectives seem to bear the 'external argument' of the deverbal noun, not its internal one (i.e. they pattern like ethnic adjectives of the Italian invasion type, discussed in Kayne 1984; see Alexiadou \& Stavrou 2011 for a discussion of the Greek data). In SCs, the non-head generally corresponds to the internal argument of the head. Typical affixes used to derive adjectives out of names include, $-i k$ - and $-i-$ :

(48) merkel-ik-i litotita tsipr-i-a logiki

'Merkel austerity' 'Tsipras logic'

Alexiadou \& Stavrou (2011) have proposed that -ik-adjectives are 'genitive-equivalent' (Marchis 2018). From their perspective, the adjective starts as nP but incorporates into an adjectival head. 
Finally, Rosenbach further observes that proper names can be anaphorically referred to, a property typically not associated with noun modifiers in compounds; see (49), from Rosenbach (2007: 148). This is very different from the Greek N-Ngen construction, where this is not possible, as shown in (50):

(49) Bush supporters would stay home, figuring he'd already won.

(Julia Hirschberg in conversation: 9 November 1988, as cited in Ward et al. 1991:469)

(50) * to shedio Marshal $_{\mathrm{i}}$ ton $_{\mathrm{i}}$ ekane diasimo

'the Marshal plan made him famous'

Proper names within adjectives are not accessible to anaphora either:

(51) $*_{\mathrm{i}} \quad$ papandre $\mathrm{iki}_{\mathrm{i} i}$ diahirisi odigise stin kritiki $\mathrm{tu}_{\mathrm{i}}$ the Papandreou management led.to the criticism his

Recently, Grant \& Alexiadou (2019) found little evidence in English that pronominal reference to non-heads in compounds is degraded at all, although there is an advantage for proper names, which are salient. This is in line with an analysis, according to which compounds in English do not involve roots, but elements that can in principle be referred to due to D-n merger. This explains the fact that while the modifier structures, e.g. Major plan and nomos Katseli, are similar in containing nPs as modifiers, only the former can be involved in pronominal reference, since it contains D, but not the latter, which is a bare nP.

\section{Conclusions}

In this article, I discussed cross-linguistic asymmetries in PNCs focusing on English vs Greek. I argued that these relate to the differences in the structure of compounding and of proper names in these two languages. As detailed in Ralli (2013), Greek differs from English in that it allows only roots as non-heads of compounds. Basically, in Greek compounding involves incorporation; by contrast, English allows for phrasal non-heads. With respect to the structure of proper names, it was shown that in English proper names can have rigid designation due to D-n merger, while in Greek rigid designation obligatorily requires a determine. As Greek right-headed compounds involve non-phrasal elements as non-heads, proper names are banned from both synthetic and root right-headed compounds in the language. By contrast, compounding is phrasal in English and as a result proper names are allowed as non-heads of right-headed compounds. As their structure contains D, they can serve as antecedents of pronouns. In Greek proper names may appear in phrasal non-deverbal compounds without articles, but have as expected a non-referential interpretation, since they are just nPs and thus understood as predicates. Greek lacks phrasal compounds with a deverbal head, as detailed in sections 2 and 4.

The analysis offered here predicts that languages that allow phrasal non-heads will generally allow compounds with proper names. By contrast, languages that have only 
root/stem left-hand non-heads will behave like Greek. Slavic languages constitute an interesting test case. These form compounds in ways very similar to Greek, and also lack proper name compounds. These languages also lack articles, suggesting that the most important ingredient is the constraint on the size of non-heads in right-headed compounds.

Importantly, this analysis explains another little-discussed point of cross-linguistic variation. Germanic languages allow the formation of phrasal compounds productively, as shown in (52); see, e.g., contributions in Trips \& Kornfilt (2015, 2017):

(52) English (cited in Wiese 1996):

a pipe-and-slipper husband a slept-all-day look

Greek lacks such compounds:

(53) *[PP me tin próti matjá]-(o)-érotas

with the first sight -LE-love

int.: 'love at first sight'

(Bagriacik \& Ralli 2015)

Wiese (1996) adopts Partee (1973) and analyzes phrasal compounds as quotes. While there is some controversy as to the proper analysis of quotes, one theory that has been entertained in the literature is the so-called proper name theory of quotation (see, e.g., Tarski 1933; Quine 1940; Johnson 2018; Cappelen et al. 2019). According to Tarski (1933: 159),

every quotation-mark name is then a constant individual name of a definite expression (the expression enclosed by the quotation marks) and is in fact a name of the same nature as the proper name of a man.

Assuming that quote compounds are like proper-name compounds, their ban in Greek follows from the general ban on phrasal elements as non-heads in right-headed compounds. As left-headed compounds do not allow recursion, quote compounds are simply not found in Greek and other languages of this type.

Author's addresses:

Department of English and American Studies

Humboldt Universität zu Berlin

Unter den Linden 6

10099 Berlin

Germany

artemis.alexiadou@hu-berlin.de

Leibniz-Zentrum Allgemeine Sprachwissenschaft

Schützenstr. 18

10117 Berlin

Germany 


\section{References}

Abney, Steven. 1987. The English noun phrase in its sentential aspect. PhD dissertation, MIT.

Alexiadou, Artemis. 2001. Functional structure in nominals: Nominalization and ergativity. Amsterdam: John Benjamins.

Alexiadou, Artemis. 2017a. On the complex relationship between deverbal compounds and argument supporting nominals. In Maria Bloch-Trojna \& Anna Malicka-Kleparska (eds.), Aspect and valency in nominals, 31-52. Berlin: Mouton de Gruyter.

Alexiadou, Artemis. 2017b. Gender and nominal ellipsis. In Nicholas LaCara, Keir Moulton \& Anne-Michelle Tessier (eds.), A schrift to fest Kyle Johnson (Linguistics Open Access Publications 1), 11-22. Amherst, MA: ScholarWorks@UMass.

Alexiadou, Artemis, Liliane Haegeman \& Melita Stavrou. 2007. Noun phrase in the generative perspective. Berlin: Mouton de Gruyter.

Alexiadou, Artemis \& Melita Stavrou. 1997. Crosslinguistic asymmetries in N-movement: Aview from morphology. ZAS Papers in Linguistics 8, 1-16.

Alexiadou, Artemis \& Melita Stavrou. 2011. Ethnic adjectives as pseudoadjectives. Studia Linguistica $65,1-30$.

Alexopoulou, Theodora \& Rafaella Folli. 2011. Indefinite topics and the syntax of nominals in Italian and Greek. Online Proceedings of West Coast Conference on Formal Linguistics 28, https://docs. google.com/viewer?a=v\&pid=sites\&srcid=ZGVmYXVsdGRvbWFpbnx3Y2NmbDI4cHJvfGd 4OjRjNTI1ZTJhNGJiMTNjODc\&pli=1 (accessed 28 April 2019).

Alexopoulou, Theodora, Rafaella Folli \& George Tsoulas. 2013. Bare number. In Rafaella Folli, Christina Sevdali \& Robert Truswell (eds.), Syntax and its limits, 300-23. Oxford: Oxford University Press.

Anastasiadi-Simeonidi, Anna. 2002. Antistrofo leksiko tis Neas Ellinikis [Reverse dictionary of Modern Greek]. Thessaloniki: Institute for Modern Greek Studies.

Arad, Maya. 2005. Roots and patterns - Hebrew morpho-syntax. Dordrecht: Springer.

Bagriacik, Metin \& Angela Ralli. 2015. Phrasal vs. morphological compounds: Insights from Modern Greek and Turkish. STUF - Language Typology and Universals 68, 323-59.

Baker, Mark. 1988. Incorporation. Chicago: Chicago University Press.

Borer, Hagit. 2005. In name only. Oxford: Oxford University Press.

Breban, Tine. 2018. Proper names used as modifiers: A comprehensive functional analysis. English Language and Linguistics 22(3), 381-401.

Breban, Tine, Julia Kolkmann \& John Payne. 2019. The impact of semantic relations on grammatical alternation: An experimental study of proper name modifiers and determiner genitives. English Language and Linguistics 23(4), 797-826.

Burge, Tyler. 1973. Reference and proper names. Journal of Philosophy 70, 425-39.

Cappelen, Herman, Ernst Lepore \& Matthew McKeever. 2019. Quotation. In Edward N. Zalta (ed.), The Stanford encyclopedia of philosophy. Spring 2019 edition. https://plato.stanford.edu/ archives/spr2019/entries/quotation/

Cinque, Guglielmo. 1993. On the evidence for partial N-movement in the Romance DP. University of Venice Working Papers in Linguistics 3(2), 21-40.

Embick, David. 2010. Localism vs. globalism in morphology and phonology. Cambridge, MA: MIT Press.

Fara, Delia. 2015. Names are predicates. Philosophical Review 124, 59-117.

Ghomeshi, Jila \& Diane Massam. 2009. The proper D connection. In Jila Ghomeshi, Ilana Paul \& Diane Massam (eds.), Determiners: Universals and variation, 67-96. Amsterdam: John Benjamins.

Giegerich, Heinz. 2004. Compound or phrase? English noun-plus-noun constructions and the stress criterion. English Language and Linguistics 8, 1-24. 
Grant, Margaret \& Artemis Alexiadou. 2019. Pronominal reference to proper names in compounds. In A. Gattnar, R. Hörnig, M. Störzer \& S. Featherston (eds.), Proceedings of Linguistic Evidence 2018: Experimental data drives linguistic theory. Tübingen: University of Tübingen. https://publikationen.uni-tuebingen.de/xmlui/handle/10900/87132

Harley, Heidi. 2009. Compounding in Distributed Morphology. In Rochelle Lieber \& Pavol Stekauer (eds.), The handbook of compounding, 122-49. Oxford: Oxford University Press.

Heycock, Caroline \& Roberto Zamparelli. 2003. Coordinated bare definites. Linguistic Inquiry 34 (3), 443-69.

Heycock, Caroline \& Roberto Zamparelli. 2005. Friends and colleagues: Plurality, coordination, and the structure of DP. Natural Language Semantics 13, 201-70.

Horrocks, Geoffrey \& Melita Stavrou. 1987. Bounding theory and Greek syntax: Evidence for wh-movement in NP. Journal of Linguistics 23, 79-108.

Huddleston, Rodney \& Geoffrey Pullum. 2002. The Cambridge grammar of the English language. Cambridge: Cambridge University Press.

Iordachioaia, Gianina, Artemis Alexiadou \& Andreas Pairamidis. 2017. Morphosyntactic sources of compounding in English and Greek. Journal of Word Formation 1, 45-70.

Johnson, Michael, 2018. Pure quotation and natural naming. Journal of Philosophy 115(10), 550-66.

Kayne, Richard. 1984. Connectedness and binary branching. Dordrecht: Foris.

Kechagias, Axiotis. 2005. Generating words: Compounding in Modern Greek. MA thesis, University College London.

Kolliakou, Dimitra. 2003. Nominal constructions in Greek: Implications for the architecture of grammar. Stanford: CLSI Publications.

Koptjevskaja-Tamm, Maria. 2013. A Mozart sonata and the Palme murder: The structure and uses of proper-name compounds in Swedish. In Kersti Börjars, David Denison \& Alan Scott (eds.), Morphosyntactic categories and the expression of possession, 253-90. Amsterdam: John Benjamins.

Lazaridou-Chatzigoga, Dimitra. 2009. On definiteness and the occurrence of the definite article with other determiners in Modern Greek. PhD dissertation, Universidad Autónoma de Barcelona.

Longobardi, Giuseppe. 1994. Reference and proper names. Linguistic Inquiry 25, 609-65.

Marantz, Alec. 2013. Locality domains for contextual allomorphy across the interfaces. In Ora Matushansky \& Alec Marantz (eds.), Distributed Morphology today: Morphemes for Morris Halle, 95-116. Cambridge, MA: MIT Press.

Marchis Moreno, Mihaela. 2018. Relational adjectives in Romance and English: Mismatches at the interfaces. Cambridge: Cambridge University Press.

Matushansky, Ora. 2006. Why Rose is the Rose. Empirical Issues in Formal Syntax and Semantics 6, 285-308.

Matushansky, Ora. 2008. On the linguistic complexity of proper names. Linguistics and Philosophy 31, 573-627.

Michelioudakis, Dimitris \& Nikos Angelopoulos. 2013. The syntactic status of N-incorporation in de-verbal compounds: Synchronic and diachronic evidence. Studies in Greek Linguistics 33, 209-27.

Ntelitheos, Dimitris. To appear. A syntactic analysis of synthetic and phrasal compound formation in Greek. In Sumru Öszoy \& Ayse Gürel (eds.), Current issues in Mediterranean syntax.

Partee, Barbara H. 1973. The syntax and semantics of quotation. In Stephen R. Anderson \& Paul Kiparsky (eds.), A festschrift for Morris Halle, 410-18. New York: Holt, Rinehart and Winston.

Plag, Ingo. 2006. The variability of compound stress in English: Structural, semantic and analogical factors. English Language and Linguistics 10, 143-72. 
Quine, Willard Van Orman. 1940. Mathematical logic. Boston, MA: Harvard University Press. Ralli, Angela. 2002. Domi ke Shimatismos Lekseon tis Kinis Neoellinikis [Structure and formation of words of standard Modern Greek]. In Mentor: idiki ekdosi gia tin elliniki glossa ston 21o eona [Mentor: special issue on the Greek language in the 21st century], 201-27.

Ralli, Angela. 2013. Compounding in Modern Greek. New York: Springer.

Ritter, Elisabeth. 1991. Two functional categories in noun phrases: Evidence from Modern Hebrew. In Susan Rothstein (ed.), Syntax \& Semantics 26, 37-62. San Diego: Academic Press.

Rosenbach, Anette. 2007. Emerging variation: Determiner genitives and noun modifiers in English. English Language and Linguistics 11, 143-89.

Schlücker, Barbara. 2013. Non-classifying compounds in German. Folia Linguistica 47, 449-80.

Tarski, Alfred. 1933. The concept of truth in formalized languages. In Alfred Tarski (ed.). 1983. Logic, semantics, metamathematics, 152-278. Indianapolis: Hackett.

Trips, Carola \& Jaklin Kornfilt. 2015. Introduction. STUF - Language Typology and Universals 68, 233-40.

Trips, Carola \& Jaklin Kornfilt (eds.). 2017. Further investigations into the nature of phrasal compounding. Berlin: Language Science Press.

Ward, Gregory, Richard Sproat \& Gail McKoon. 1991. A pragmatic analysis of so-called anaphoric islands. Language 67(3), 439-74.

Wiese, Richard. 1996. Phrasal compounds and the theory of word syntax. Linguistic Inquiry 27, 183-93. 